\title{
Study on the microstructure and impact fracture behavior of martensitic alloy steels
}

\author{
Z. B. Zheng ${ }^{1 *}$, J. Long ${ }^{1}$, K. H. Zheng ${ }^{1}$, H. L. Zhou ${ }^{2 * *}$, H. Li ${ }^{1}$, Q. L. Zhang ${ }^{1}$ \\ ${ }^{1}$ Guangdong Key Laboratory for Technology and Application of Metal Toughening, \\ Guangdong Institute of Materials and Processing, no. 363 Changxing Road, Guangzhou 510650, P. R. China \\ ${ }^{2}$ School of Materials Science and Engineering, Jiangsu University of Science and Technology, \\ no. 2 Mengxi Road, Zhenjiang 212003, P. R. China
}

Received 24 December 2018, received in revised form 1 February 2019, accepted 13 February 2019

\begin{abstract}
Martensitic steels used for ball mill liners were prepared. The effect of tempering on the microstructures, Rockwell hardness, and impact toughness of the tested steels was evaluated at room temperature. The fracture morphologies were observed by using metallurgical microscopy, scanning electron microscopy and energy-dispersive spectroscopy. The results showed that tempering decreased the Rockwell hardness and significantly improved the impact toughness of the tested steel. However, the impact toughness of the tempered steels was unstable. Fracture of the tested steel before tempering was quasi-cleavage fracture; however, it changed to ductile and quasi-cleavage fracture after tempering. Carbide segregations formed at the local grain boundaries became the crack source and were the preferred ways for crack propagation during the impact test. The existence of segregations was inferred to be the main reason for the fluctuation of impact toughness.
\end{abstract}

K e y words: martensitic steel, tempering, mechanical properties, fracture

\section{Introduction}

Grinding is the process of reducing the size of materials into fine particles and is emerging as one of the most important processes in the mining industry. It is unavoidable in nearly all mineral processing [1]. During the process, ores and grinding balls are lifted by the lifter bar on the liners to a certain height, and then they fall onto the bottom of the mill to complete the crushing [2]. The liner bears not only the wear damage from the ores but also the impact damage from the ores and grinding balls in different degrees. In addition, the ball mill liner suffers corrosion from the corrosive slurry under a wet-milling condition [3]. Based on the functions of the mill liners, the employed materials must exhibit an adequate combination of wear resistance and impact toughness [4]. It is reported that the traditional materials used in the mining industry, manganese steel liners, have a life of no more than one year. Maximizing the liner life is of particular importance because the cost of replacement includes not only the cost of the replacement components but also the cost of lost production during change-out $[5,6]$. The estimated economic losses resulting from friction and wear in mineral mining reach total 210000 million euros annually [7]. Therefore, it is necessary to find suitable materials with high performance to be used for grinding balls and ball mill liners.

Martensitic steel is one of the alloy steels with high hardness and wear resistance. After proper heat treatment and micro-alloying treatment, the corrosion resistance and impact toughness can also be acceptable. Thus, it shows excellent application prospects on wear-resistant components in industries such as mining, cement, and power. Du et al. [8] compared the impact corrosion and abrasion resistance of low-carbon high-alloy steel, high-manganese steel, and mediumcarbon-alloy steel in the acid-ironstone slurry and the result showed that low-carbon high-alloy steel with martensitic structure was the best. Ratia et al. [9] discovered that ferrite in the microstructure of the 650 HB steel with a martensitic matrix seemed to pro-

\footnotetext{
*Corresponding author: tel.:+86 206108 6183; fax:+86 206108 6616; e-mail address: zbzheng712003@163.com
}

**Corresponding author: e-mail address: zhouhl@just.edu.cn 
Table 1. Heat treatments of alloy steel

\begin{tabular}{lccc}
\hline Processes & Annealing & Quenching & Tempering \\
\hline Holding temperatures & $1020-1050^{\circ} \mathrm{C}$ & $980-1000^{\circ} \mathrm{C}$ & $220-250^{\circ} \mathrm{C}$ \\
Holding times & $5 \mathrm{~h}$ & $4 \mathrm{~h}$ & $6 \mathrm{~h}$ \\
Cooling conditions & In furnace & In oil & In air \\
\hline
\end{tabular}

mote deformation of the martensite around the ferrite grains, but this did not have a notable effect on the overall wear resistance of the material compared with fully martensitic wear resistant steels. Fu et al. [10] designed a boron alloy steel that contained martensite and found that the servicing cycle is 1.6-times longer than that of high manganese steel liner. Gates et al. [6] concluded that only very hard (more than $630 \mathrm{HV}$ ) martensitic steels and white cast irons offered large performance benefits when grinding abrasives whose Mohs hardness was less than approximately six. Efremenko and his colleagues [11] recommended a martensitic structure in steels containing not less than 13-wt.\% Cr. $\mathrm{Lu}$ and $\mathrm{Li}[12]$ carried out a review that shows that the $\mathrm{Fe}-\mathrm{Cr}$ martensite alloy steel is one of the most suitable materials for the ball mill liner in a mine wet-grinding machine.

Although martensitic steel has attracted much attention in the mining industry, a prominent defect is that the impact toughness of this steel cannot meet requirements usually. Fluctuant results of impact toughness have been discovered in several studies [13, 14], and fluctuation may be a potential risk for the application of steels in ball mill liners. Users have reported that cracks have been discovered in some of the Fe-Cr alloy steels after service of only two weeks. Thus, there is a great risk in using the material, although the properties of it in the laboratory were sufficient. The reason is still unclear.

In the current work, martensitic steels have been prepared for ball mill liners. To study the stability of their performance, ball mill liners of the chosen compositions were cast directly, and the specimens were cut from the huge liners. The effect of tempering treatment on the microstructures and mechanical properties, including Rockwell hardness and impact toughness at room temperature, was investigated to evaluate the performance of the alloy steel. Unstable results for impact toughness were discovered, and the internal reason was revealed by fracture analysis. The result provides an important reference for designing liners using martensitic steel.

\section{Experimental materials and procedure}

The material prepared in the current study was designed based on previous studies [15] as follows: $\mathrm{Cr}$ :
7.0-8.0\%, C: 0.35-0.38\%, Si: 0.45\%, Mn: $0.55 \%$, Ni: $0.50 \%, \mathrm{~S} \leq 0.04 \%$, and $\mathrm{P} \leq 0.04 \%$. An intermediate frequency furnace was used to melt the raw materials, and the whole ball mill liners with a weight of nearly $300 \mathrm{~kg}$ were finally cast. To achieve martensite in the final alloy structure, heat treatments, including annealing, quenching, and tempering, were conducted. Detailed parameters of the processes are shown in Table 1 .

After heat treatments, the ingots were cut into coupons of $15 \times 15 \times 10 \mathrm{~mm}^{3}$ used for metallographic observation and $10 \times 10 \times 55 \mathrm{~mm}^{3}$ (unnotched) for the impact test. All specimens were cleaned with acetone in an ultrasonic cleaner. Metallographic specimens were polished by abrasive papers and polished down to a diamond finish of $1.5 \mu \mathrm{m}$ and then etched using a mixed solution with $1 \mathrm{wt} . \%$ picric acid $\left(\mathrm{C}_{6} \mathrm{H}_{3} \mathrm{~N}_{3} \mathrm{O}_{7}\right), 5$ wt. $\%$ hydrochloric acid $(\mathrm{HCl})$, and alcohol $\left(\mathrm{CH}_{3} \mathrm{CH}_{2} \mathrm{OH}\right)$.

The microstructures of the specimens were analyzed by Leica DMI 3000M optical metallographic microscope. The impact test was conducted at room temperature using a JBN500 impact tester. After the impact tests, the fracture morphologies were characterized by Nova Nano SEM 430 Scanning Electron Microscope (SEM) and Energy Disperse Spectroscopy (EDS). To analyze the initiation and propagation of cracks further, the side of the fracture surface was also observed. The hardness of specimen was examined with an HR-150A Rockwell hardness tester. The final result was a value from averaged over five tests. Each test was repeated at least three times to ensure the reproducibility.

\section{Results and discussion}

\subsection{Microstructure of alloy steels}

Figure 1 shows the metallurgical structure of tested steel before (Fig. 1a,b) and after (Fig. 1c,d) tempering. The structure contains martensite mainly, which is consistent with the designing structure. It is apparent that light-colored and dark-colored regions appear in the microstructures of alloy steels. From the enlarged view in Fig. 1b, a certain amount of lath martensite has been observed in the light-colored region, which demonstrates that the light-colored region 

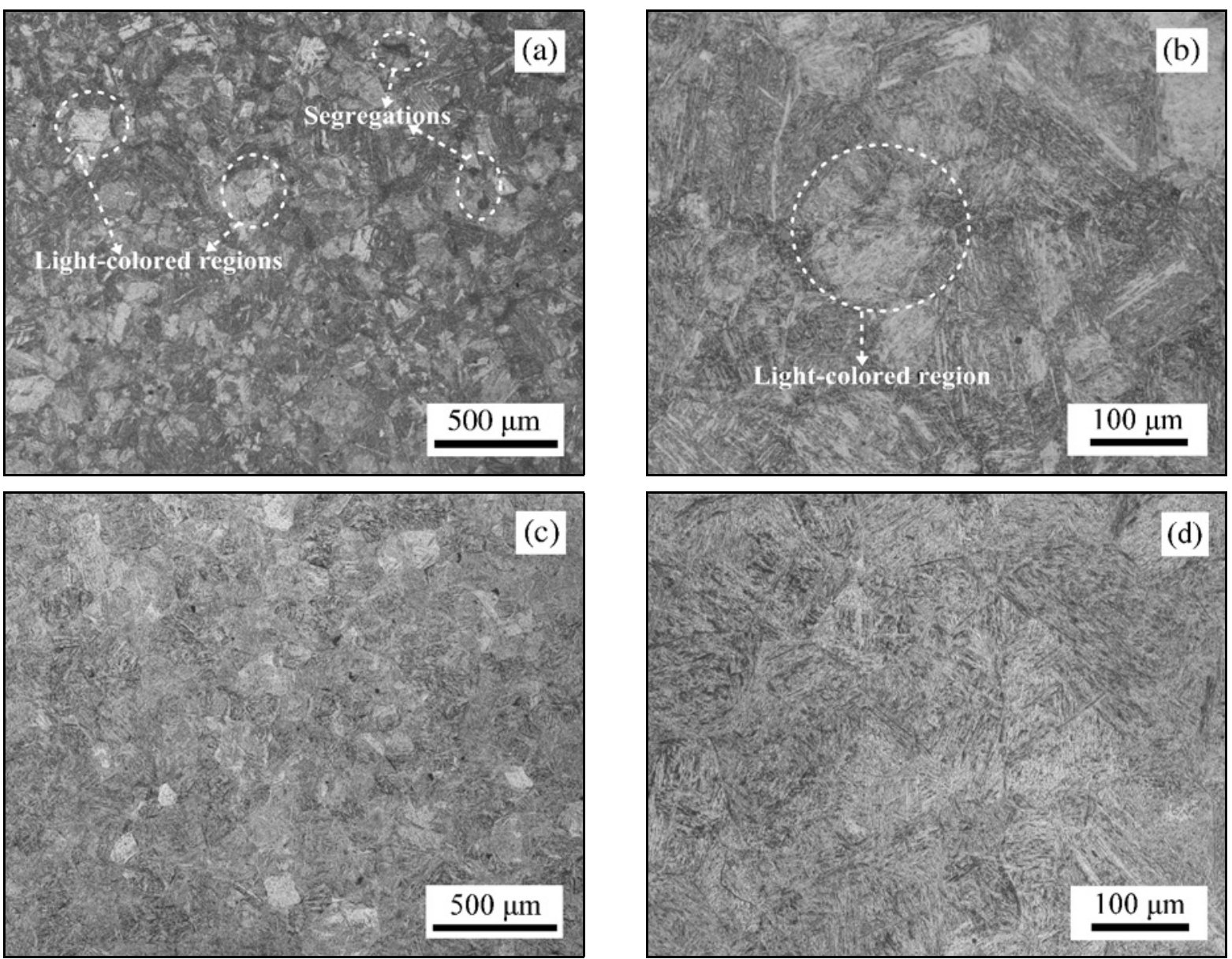

Fig. 1. Metallurgical structures of alloy steels before tempering (a), (b) and after tempering (c), (d).

also consists of martensite. It is inferred that the different regions are lath martensite developed during martensitic transformation because of the differences in transformation sequences and temperature [16, 17]. The martensite in the dark regions was supposed to be formed at a later stage of martensite transformation, which maintained a high dislocation density. The martensite in the light-color regions was supposed to be formed at the beginning of the martensite formation with a relatively high temperature and exhibited reasonably low dislocation density because of greater recovery of dislocations throughout the extended period of transformation [18]. At the same time, residual austenite gradually transformed into martensite that is dark. In addition, segregations had been discovered in the steel before tempering $[19,20]$. The stability of the material properties may be affected by these segregations.

In contrast, the light-colored regions in the tempered alloy steel were less than those of the untempered steel, which indicates that changes took place in martensite during the tempering process, or phase transformation occurred for the retained austenite. It is well known that, during the tempering of steels al- loyed with carbide-forming elements (e.g., Cr, $\mathrm{Mn}$, and Mo), cementite can form with partitioning of these alloying elements, and the interlath film, such as retained austenite, decomposes into ferrite $(\alpha)$ and cementite $\left(\theta-\mathrm{Fe}_{3} \mathrm{C}\right)[21-23]$. In addition, the problem of segregation in the structure of steel after tempering was alleviated, and the uniformity of the steel improved. This is mainly attributed to the tempered martensite transformation during heat treatment.

\subsection{Mechanical properties of alloy steels}

Figure 2 shows the Rockwell hardness of the tested steel. The Rockwell hardness of the tested steel before and after tempering was 55.7 and 50.3 HRC, respectively. Tempering decreases the hardness of steel. This is mainly because of the decomposition of martensite during tempering and the ejection of carbon atoms from the carbon supersaturated martensite phase [24]. The key element carbon that greatly contributes to the high hardness in martensite has been consumed to form carbides.

Figure 3 shows the impact toughness of the tested steel before and after tempering. The result shows a 


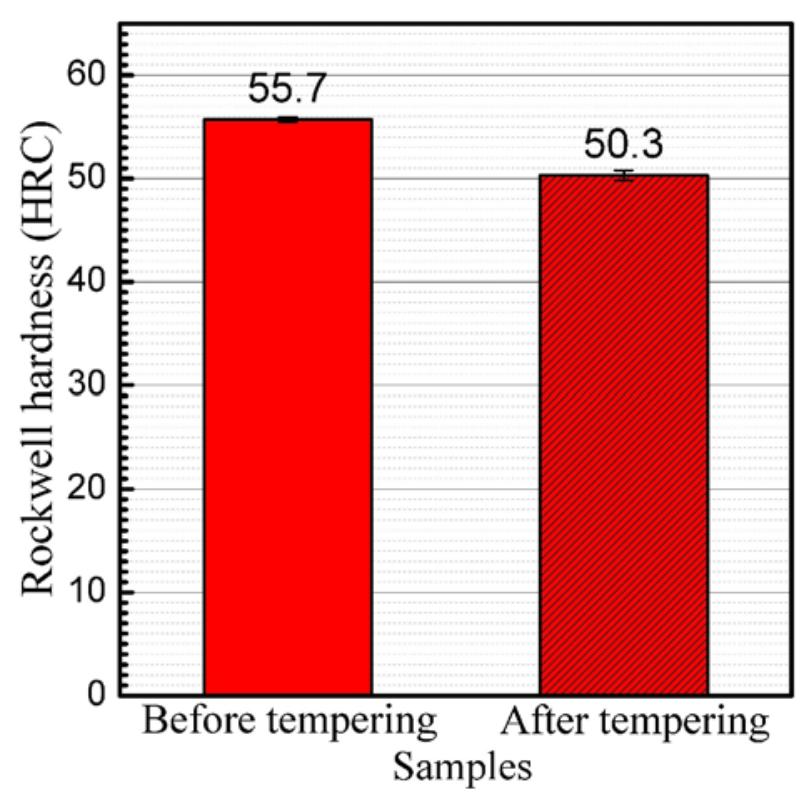

Fig. 2. Rockwell hardness of alloy steels.
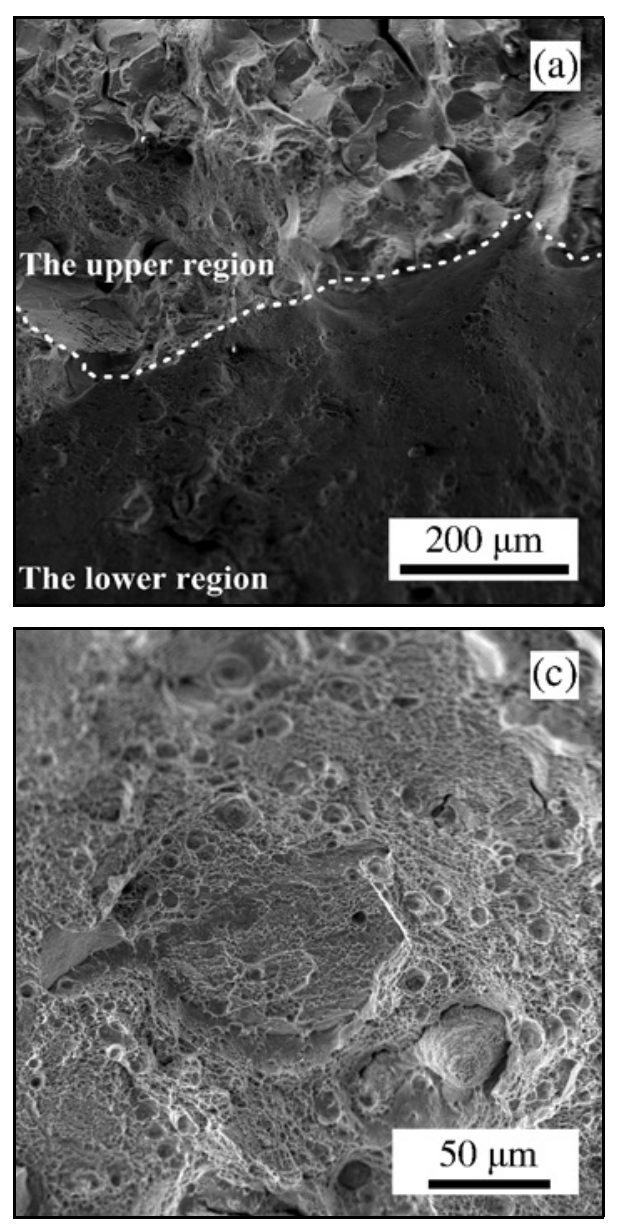

Fig. 4. Fracture morphologies of the tempered steel.

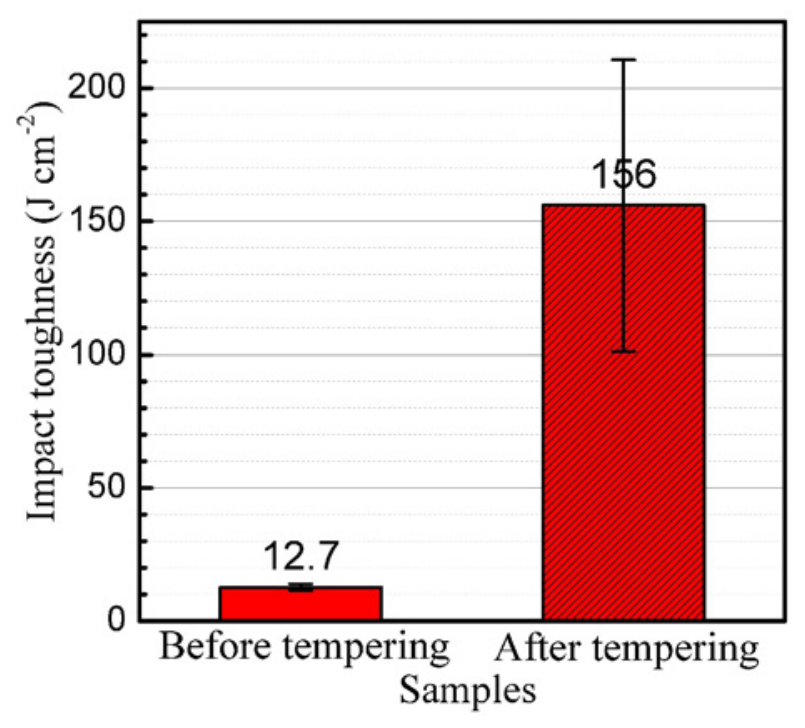

Fig. 3. Impact toughness of alloy steels at room temperature.
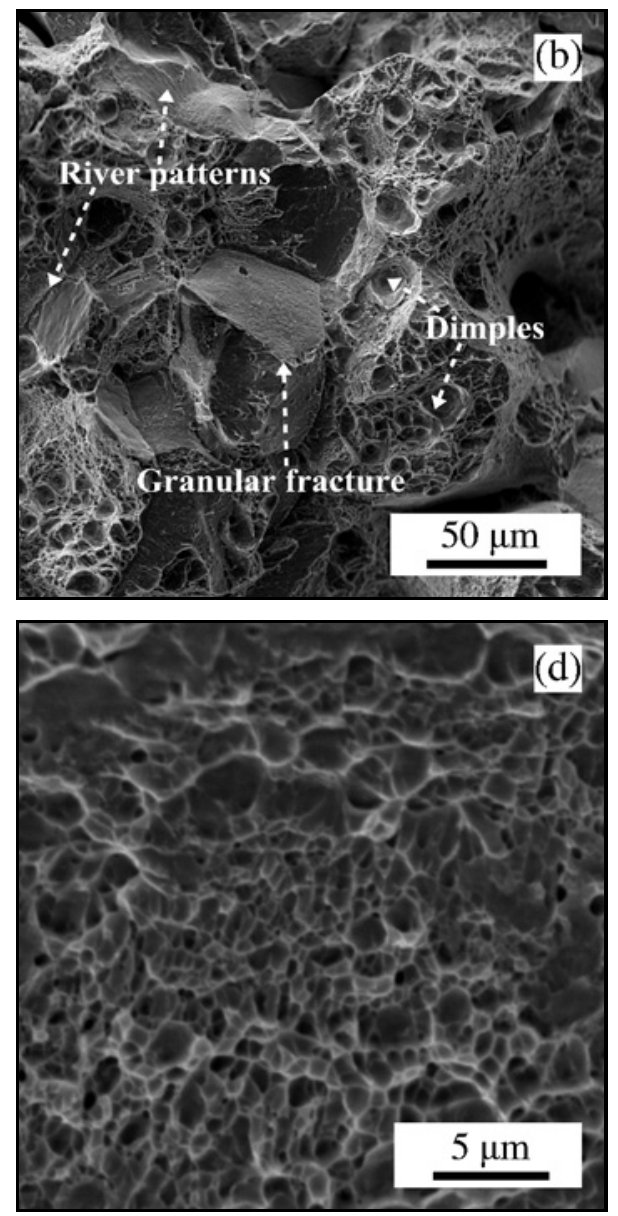
large difference between the alloy steels before and after tempering. The impact toughness of the untempered specimen was $12.7 \mathrm{~J} \mathrm{~cm}^{-2}$, whereas the result after tempering was significantly improved to $156 \mathrm{~J} \mathrm{~cm}^{-2}$. Tempering of martensitic steels is essential to suppress brittle fracture and ensure the desired combination of strength and ductility. Therefore, tempered martensite has received increasing attention and is becoming one of the phases present in most of the advanced high strength steels [25]. However, the process of tempering is complex for different martensite steels. In the current work, the main reasons for the different properties are inferred as follows. First, the cooling rate for the quenching of steel in oil was relatively fast, resulting in high residual stress in the specimen. During the impact test, the residual tensile stress promoted the initiation and propagation of cracks, and the specimen was easily fractured. However, it is well known that tempering is effective in eliminating residual stress [26]. Therefore, the resistance of the tempered specimen to fracture improved. Second, the transition carbides precipitated during the tempering process were coherent with the matrix, therefore hindering the motion of dislocations and, thus, raising the strength of the steel [27]. Additionally, segregation may be an important reason for the low impact toughness of specimens before tempering. As shown in Fig. 1, segregations around the grain boundary were sensitive to fracture. It is very interesting, but confusing, that the specimens after tempering exhibited fluctuant results for impact toughness.

\subsection{Fracture morphologies of the specimen after tempering}

The fracture morphologies of the tempered parallel specimen are shown in Fig. 4. The fracture morphologies are complex. Two different regions are shown in Fig. 4a. The upper region (Fig. 4b) of the figure shows the quasi-cleavage fracture. It is a fracture mode between cleavage fracture and dimple fracture [28-30]. River patterns, granular fractures, and dimples are the main features of this region. Cracks initiate at different positions of the structure and then propagate discontinuously. The granular fracture region shows a smooth interface (Fig. 4b), which is different from the rough dimple fracture. Generally, this type of fracture occurs because of the precipitation of continuously or discontinuously distributed brittle phases along the grain boundary. Under the action of external tensile forces, the weak precipitates are easily damaged, and cracks start to propagate along the grain boundary, resulting in the fracture of the specimen. The lower region shows an obvious ductile fracture characteristic, which is more evident from the enlarged Fig. 4c,d [31]. A large
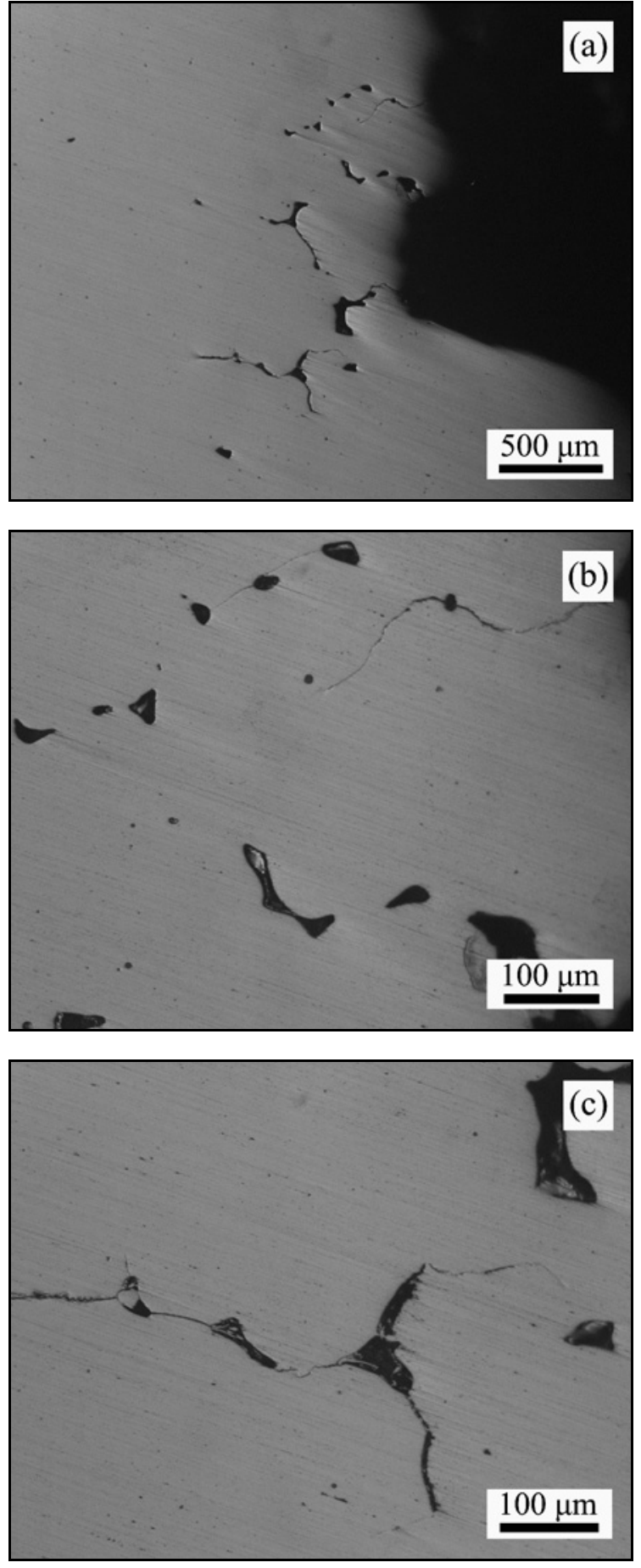

Fig. 5. The side view of the fractured specimen.

number of dimples have been discovered in this region.

\subsection{Initiation and propagation of cracks}

To reveal the reasons for the unstable impact toughness of tempered steels, the initiation and propagation of cracks were studied further. The reverse side 

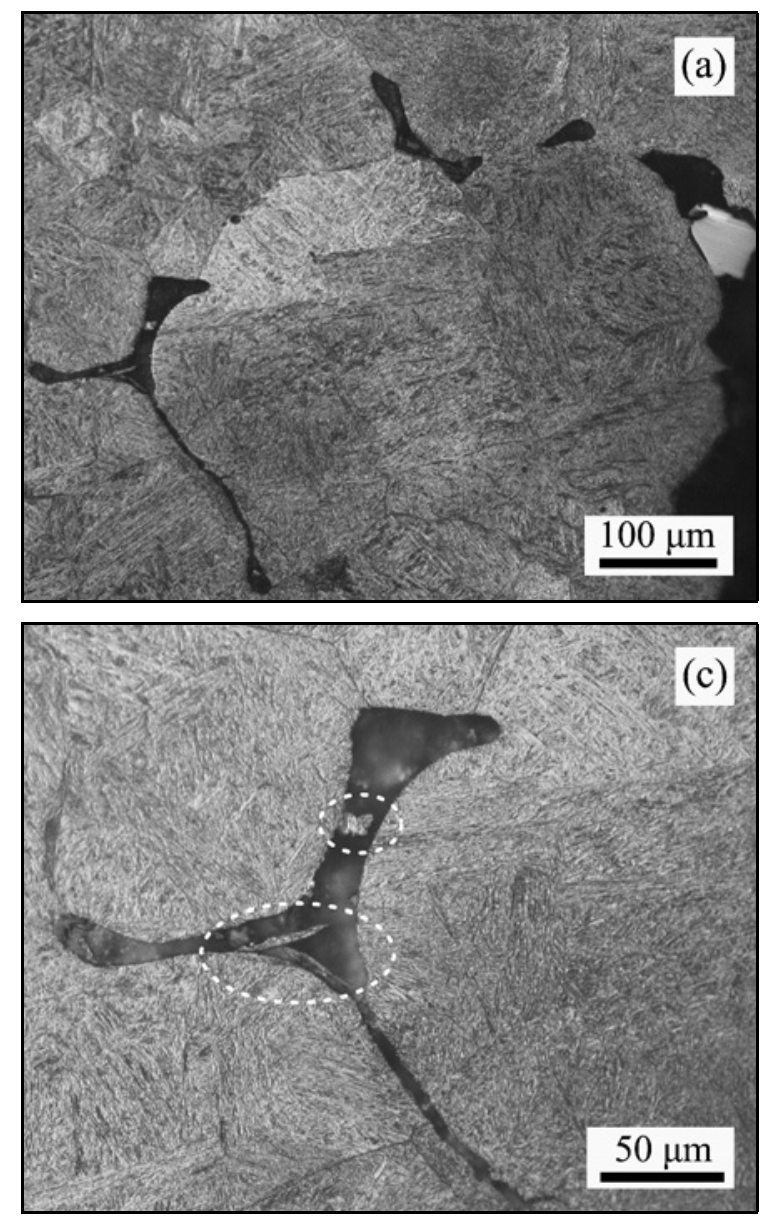
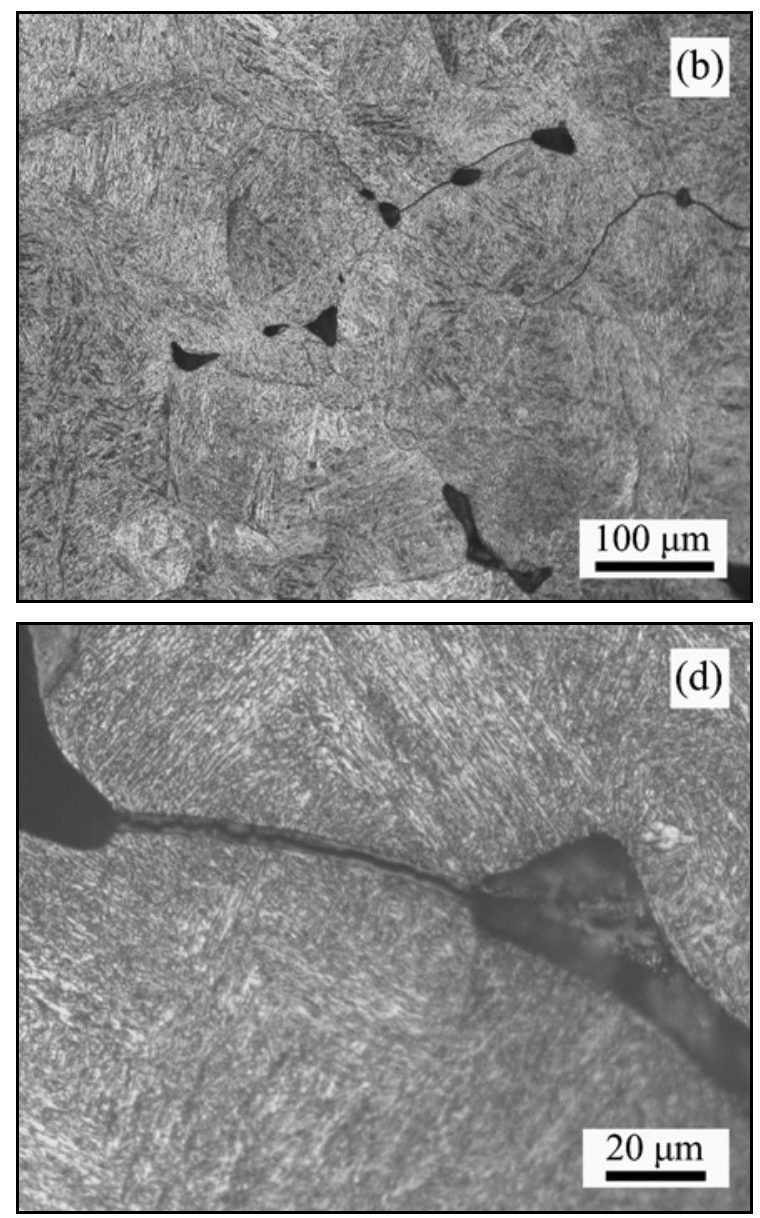

Fig. 6. Metallurgical structures showing the side of the impact fracture of the etched specimen.

of the impact surface after fracture was evaluated by a metallurgical microscope. It is certain that this surface suffered tension stress during the process of impact.

Figure 5 is the metallurgical structure showing the side of the fractured surface. Many holes were discovered at the edge of the fracture. The shapes of the holes were not the same. Some of them appeared island-like, whereas others were irregular strips. The causes for the formation of the holes are as follows. First, they were the casting defects, such as looseness and gas holes, which formed before the impact test of the specimen. Second, they may have resulted from the smashing of some weak phases or structures when subjected to strong tensile stress during the impact test. It is certain that these holes greatly affected the impact resistance of the alloy steel. They provided the position and condition for the initiation of cracks. Also, cracks tended to propagate along the connection path of adjacent holes.

The etched side view of the fractured specimen is shown in Fig. 6 to show further the reason for the formation of holes. The microstructure of the specimen after impact was still martensite. Most of the holes distributed along grain boundaries, and there were no obvious holes inside the grain. The distribution feature of holes can provide preferred ways for crack propagation during the impact process. Cracks expanded easily between two holes, as seen in Fig. 6d, finally leading to a bigger one. A significant discovery shown in Fig. 6c is that there were residual materials in the holes, as circled in the figure. This discovery indicates that the holes in the specimen were not casting defects, such as looseness or gas holes formed during the casting process. This result was most probably caused during the deformation, crushing, and detachment of some special structures during the impact process.

It is interesting to investigate whether the structures of the holes and the matrix were the same. This investigation was carried out on the structures of the specimen, as shown in Fig. 7.

Several segregation zones were found in the tested steel. A large number of fine particles were inside the segregation regions. Interestingly, the shape of the segregation zone appears as "island-like" and "bone-like" shapes that exactly match the shapes of the holes observed above. These special zones occurred along the grain boundary, which is consistent with the distribution of holes. This coincidence implies that the formation of holes was caused by the destruction of the segregation zones in the alloy steel during impact. 
Table 2. Energy spectrum analysis of the white dots in the segregation zone

\begin{tabular}{lccccc}
\hline Elements & $\mathrm{C}$ & $\mathrm{Si}$ & $\mathrm{Cr}$ & $\mathrm{Fe}$ & $\mathrm{Mn}$ \\
\hline (wt.\%) & 16.31 & 0.49 & 21.33 & 60.16 & 0.84 \\
(at.\%) & 46.94 & 0.60 & 14.18 & 37.24 & 0.53 \\
\hline
\end{tabular}
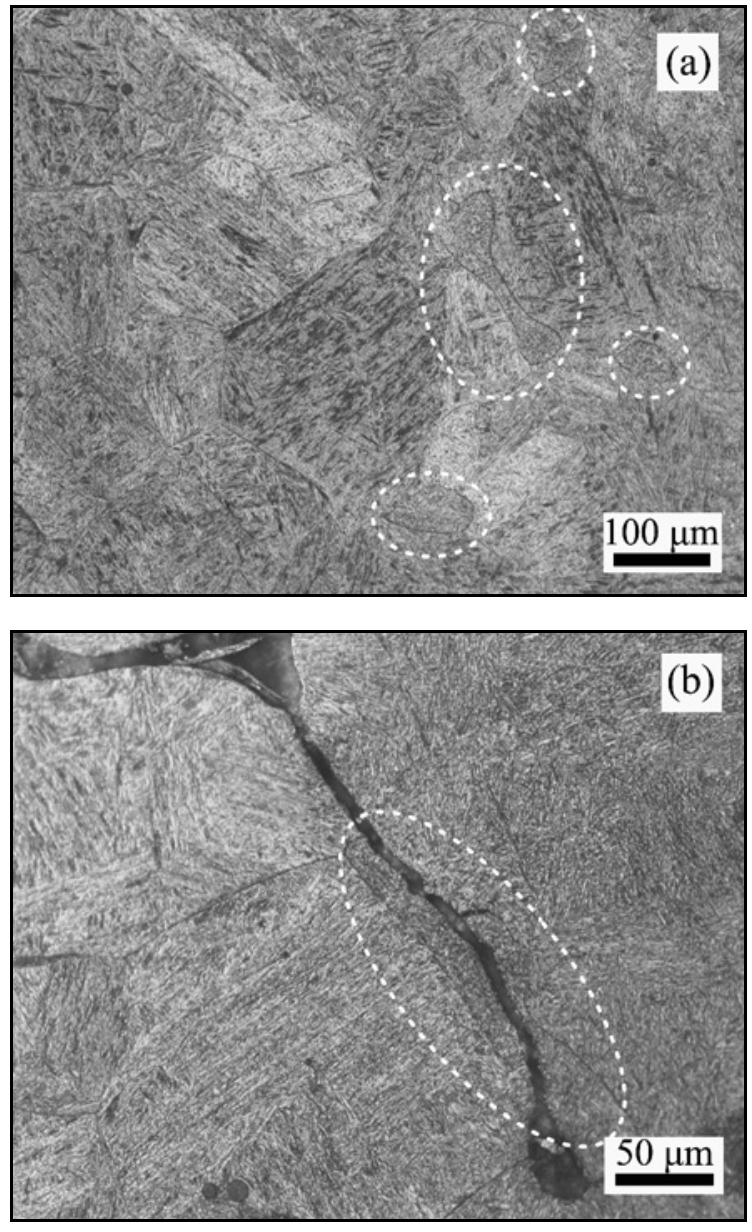

Fig. 7. Metallurgical structures showing the special zones.

The localized structure segregation was the main reason for the formation of holes and the development of a large number of cracks in the specimen. SEM was used to observe the segregation zone shown in Fig. 7b and the result is shown in Fig. 8. Many white dots were detected in the bonelike segregation zone. The further analysis from EDS (as shown in Table 2) indicates that the white dots are mainly Fe-Cr carbides. Carbides usually serve as crack sources [19]. Carbides such as $\mathrm{M}_{23} \mathrm{C}_{6}$ and $\mathrm{M}_{7} \mathrm{C}_{3}$ are incoherent boundaries with the matrix structure. Because of the incoherent boundaries, there was a small gap between the matrix and the precipitate. When a small force was applied to these gaps, the gap grew into microvoids by stress concentration. The pass-through of the crack proved that

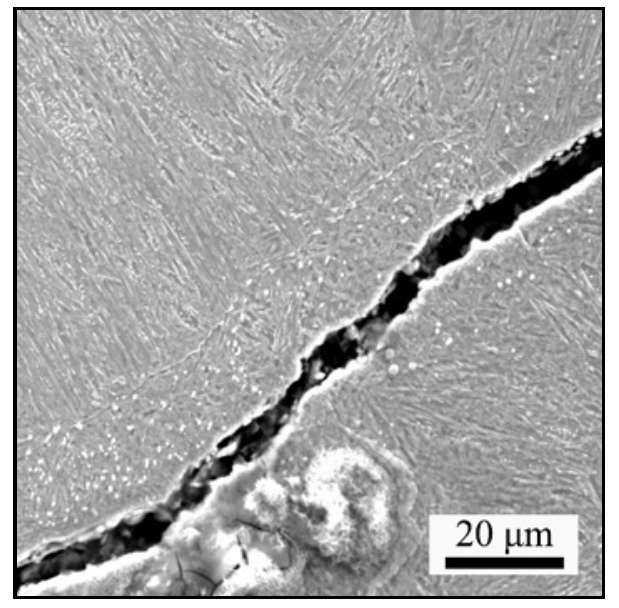

Fig. 8. Scanning electron microstructure of the segregation zone.

the segregation zone was weak in mechanical properties.

\subsection{Improvement of the martensitic alloy steel}

Wear-resistant components, especially ball mill liners that are subjected to both impact and strong wear, have high requirements on the mechanical properties of materials. Stable impact toughness is a prerequisite for safe and reliable service conditions. Based on this precondition, improving the wear resistance as much as possible is the criterion for developing high-servicelife liner materials. The highest impact toughness of the current steel can be more than $200 \mathrm{~J} \mathrm{~cm}^{-2}$, which indicates an application prospect. The key reason for the instability of impact toughness is the existence of local segregation zones along grain boundaries.

To eliminate the segregation along grain boundaries, the temperature of annealing was increased to $1100{ }^{\circ} \mathrm{C}$. After the same processes of quenching and tempering, many parallel specimens were prepared to conduct the impact test. The result of the impact toughness before and after the improvement is shown in Fig. 9. The result for the parallel specimens after the improved treatment was steadier than that of those treated at temperatures ranging from 1020 to $1050^{\circ} \mathrm{C}$. All specimens held superior impact toughness at room temperature. This indicates that increasing the annealing temperature is an effective method for 


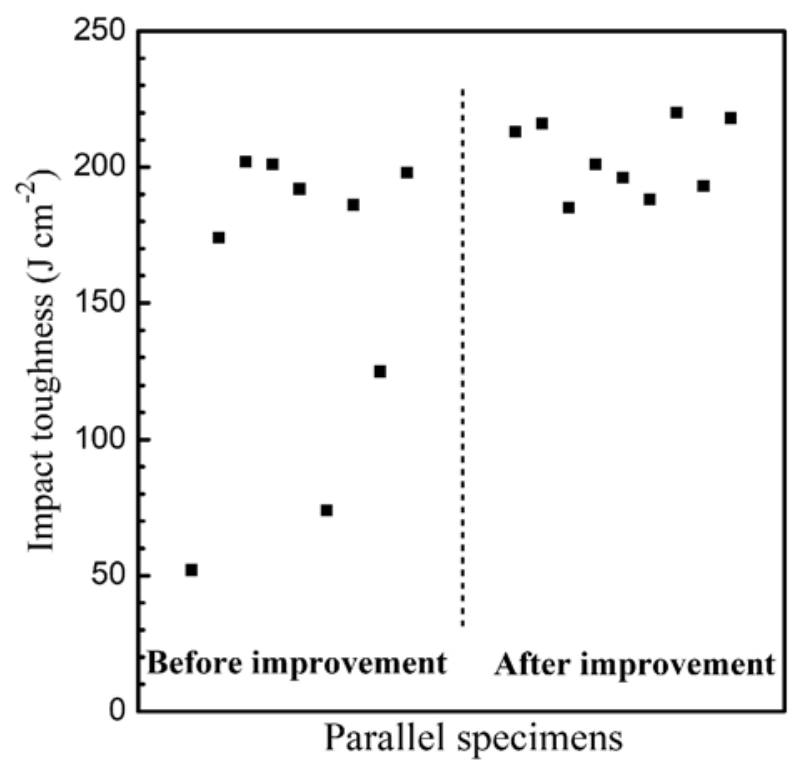

Fig. 9. Impact toughness results of the alloy steels before and after improvement.

eliminating the Fe-Cr carbides along the grain boundaries, resulting in the stability of impact toughness.

\section{Conclusions}

1. The Rockwell hardness of the martensitic alloy steel after quenching was $55.7 \mathrm{HRC}$, while its impact toughness at room temperature was only $12.7 \mathrm{~J} \mathrm{~cm}^{-2}$. Tempering could improve the mechanical properties of this alloy steel obviously. The impact toughness increased to $156 \mathrm{~J} \mathrm{~cm}^{-2}$, and the hardness remained more than 50 HRC.

2. The alloy steel after tempering had a large fluctuation in impact toughness at room temperature. The steel showed a combined fracture mode of quasicleavage fracture and ductile fracture. Many holes were found on the fracture side. Cracks generated from the holes and expanded outward along the grain boundaries.

3. The holes in the tempered steel after fracture were mainly caused by the destruction of the segregation zones during the impact process. The segregation zones contained many Fe- $\mathrm{Cr}$ carbides. To acquire martensitic alloy steel with stable high mechanical properties, it is necessary to minimize structure segregation through suitable heat treatments. Increasing the annealing temperature is an effective method.

\section{Acknowledgements}

This work was funded by GDAS' Project of Science and Technology Development (No. 2017GDASCX-
0117), Natural Science Foundation of Guangdong Province (No. 2017A030310483), Science and Technology Planning Project of Guangzhou (No. 201807010085), and Science and Technology Planning Project of Guangdong Province (Nos. 2017A070702020, 2017A070701029, 2017A050503004 and 2014B050503007).

\section{References}

[1] Gawlik, J., Schmidt, J., Nowak, T., Wójcicki, Z., Zagórski, A.: Arch. Civ. Mech. Eng., 17, 2017, p. 926. doi:10.1016/i.acme.2017.04.007

[2] Dong, H., Moys, M. H.: Miner. Eng., 16, 2003, p. 543. doi:10.1016/s0892-6875(03)00057-8

[3] Iwasaki, I., Pozzo, R., Natarajan, K., Adam, K., Orlich, J.: Int. J. Miner. Process., 22, 1988, p. 345. doi:10.1016/0301-7516(88)90072-5

[4] Shaeri, M. H., Saghafian, H., Shabestari, S. G.: J. Iron Steel Res. Int., 17, 2010, p. 53. doi:10.1016/S1006-706X(10)60059-3

[5] Peng, Y. X., Ni, X., Zhu, Z. C., Yu, Z. F., Yin, Z. X., Li, T. Q., Liu, S. Y., Zhao, L. L., Xu, J.: Tribol. Int., 115, 2017, p. 506. doi:10.1016/j.triboint.2017.06.017

[6] Gates, J. D., Dargusch, M. S., Walsh, J. J., Field, S. L., Hermand, M. J. P., Delaup, B. G., Saad, J. R.: Wear, 265, 2008, p. 865. doi:10.1016/i.wear.2008.01.008

[7] Holmberg, K., Kivikytö-Reponen, P., Härkisaari, P., Valtonen, K., Erdemir, A.: Tribol. Int., 115, 2017, p. 116. doi:10.1016/j.triboint.2017.05.010

[8] Ding, H. F., Cui, F. M., Du, X. D.: Mater. Sci. Eng. A, 421, 2006, p. 161. doi:10.1016/i.msea.2005.11.071

[9] Ratia, V., Miettunen, I., Kuokkala, V. T.: Wear, 301, 2013, p. 94. doi:10.1016/i.wear.2013.01.006

[10] Fu, H. G., Zou, D. N., Jiang, Z. Q., Yang, J., Wang, J. H., Xing, J. D.: Mater. Manuf. Process, 23, 2008, p. 469. doi:10.1080/10426910802103775

[11] Efremenko, V. G., Shimizu, K., Noguchi, T., Efremenko, A. V., Chabak, Y. G.: Wear, 305, 2013, p. 155. doi:10.1016/j.wear.2013.06.006

[12] Lu, P., Li, W.: Foundry, 60, 2011, p. 454.

[13] Du, X. D., Wang, J. Q., Sun, G. D., Man, D. H.: Mater. Sci. Eng. A, 477, 2008, p. 277. doi:10.1016/j.msea.2007.05.031

[14] Liu, C., Sun, G.: Hot Working Technology, 38, 2009, p. 19.

[15] Li, H., Zheng, Z., Long, J., Zheng, K., Wang, J.: Foundry, 67, 2018, p. 1.

[16] Morsdorf, L., Tasan, C. C., Ponge, D., Raabe, D.: Acta Mater., 95, 2015, p. 366. doi:10.1016/j.actamat.2015.05.023

[17] Saha, D. C., Biro, E., Gerlich, A. P., Zhou, Y.: Mater. Sci. Eng. A, 673, 2016, p. 467. doi:10.1016/j.msea.2016.07.092

[18] He, B. B., Huang, M. X.: Metall. Mater. Trans. A, 46, 2014, p. 688. doi:10.1007/s11661-014-2681-7

[19] Khan, F.: Metals, 8, 2018, p. 800. doi: $10.3390 / \operatorname{met} 8100800$

[20] Na, H., Lee, S., Kang, C.: Metals, 8, 2018, p. 373. doi: $10.3390 /$ met 8060373

[21] Wu, Y. X., Sun, W. W., Styles, M. J., Arlazarov, A., Hutchinson, C. R: Acta Mater., 159, 2018, p. 209. $\underline{\text { doi:10.1016/j.actamat.2018.08.023 }}$ 
[22] Qiao, Y., Jin, S., Wu, J., Chen, J., Wang, Y., Zhou, H., Tang, R.: Mater. Technol., 52, 2018, p. 745. doi:10.17222/mit.2018.091

[23] Zhao, Y. J., Ren, X. P., Hu, Z. L., Xiong, Z. P., Zeng, J. M., Hou, B. Y.: Mater. Sci. Eng. A, 711, 2017, p. 397. doi:10.1016/j.msea.2017.11.037

[24] Speich, G. R., Leslie, W. C.: Metallurgical Transactions, 3, 1972, p. 1043. doi:10.1007/BF02642436

[25] Malheiros, L. R. C., Rodriguez, E. A. P., Arlazarov, A.: Mater. Sci. Eng. A, 706, 2017, p. 38. doi:10.1016/i.msea.2017.08.089

[26] Su, C., Li, Q., Huang, X., Huang, W.: J. Iron Steel Res. Int., 25, 2018, p. 235. doi:10.1007/s42243-018-0032-4
[27] Tariq, F., Naz, N., Baloch, R. A., Ali, A.: J. Mater. Sci., 45, 2010, p. 1695. doi:10.1007/s10853-009-4160-x

[28] Merson, E., Kudrya, A. V., Trachenko, V. A., Merson, D., Danilov, V., Vinogradov, A.: Mater. Sci. Eng. A, 665, 2016, p. 35. doi:10.1016/j.msea.2016.04.023

[29] Luo, Z. C., Liu, R. D., Wang, X., Huang, M. X.: Acta Mater., 150, 2018, p. 59. doi:10.1016/j.actamat.2018.03.004

[30] Białobrzeska, B., Konat, Ł., Jasiński, R.: Metals, 7, 2017, p. 26. doi:10.3390/met7010026

[31] Zhu, Z., Zhang, W., Tu, X., Wang, X., Li, W.: China Foundry, 15, 2018, p. 182. doi:10.1007/s41230-018-7226-z 